\title{
EL DISCURSO DISTÓPICO EN LOS RELATOS DEL CINE, LA TELEVISIÓN Y LA LITERATURA: CUANDO EL FUTURO NOS ALCANZA
}

\section{THE DISTOPIC SPEECH IN THE FILM, TELEVISION AND LITERATURE STORIES: WHEN THE FUTURE REACHES US}

CARLOS AULESTIA ${ }^{1}$ SANTIAGO PÁEZ²

Recibido: 31 de enero de 2017 Aceptado: 6 de marzo de 2017

\footnotetext{
${ }^{1}$ Pontificia Universidad Católica del Ecuador, Facultad de Comunicación, Lingüística y Literatura, Escuela de Comunicación, Quito, Ecuador. (aulestia.carlos@gmail.com).

${ }^{2}$ Pontificia Universidad Católica del Ecuador, Facultad de Comunicación, Lingüística y Literatura, Escuela de Comunicación, Quito, Ecuador. (SPAEZ@puce.edu.ec).
} 



\title{
EL DISCURSO DISTÓPICO EN LOS RELATOS DEL CINE, LA TELEVISIÓN Y LA LITERATURA: CUANDO EL FUTURO NOS ALCANZA
}

\section{THE DISTOPIC SPEECH IN THE FILM, TELEVISION AND LITERATURE STORIES: WHEN THE FUTURE REACHES US.}

\author{
CARLOS AULESTIA, SANTIAGO PÁEZ
}

PALABRAS CLAVE: utopía, distopía, relatos, medios de comunicación, literatura

KEY WORDS: utopia, dystopia, story, mass media, literature

\section{RESUMEN}

En este artículo, a partir de una definición de los conceptos de utopía y distopía, y siguiendo la metodología de análisis planteada por L. Spitzer, se revisarán diez narraciones, entre literarias y de los medios de comunicación (televisión y cine). El corpus estudiado cubre casi cien años de expresiones, desde 1924 hasta
2010. En estos relatos se estudiará la manera en la que sus creadores presentan los universos distópicos. Estos universos serán vistos como proyecciones críticas de las condiciones de vida que experimenta la sociedad humana en el mundo contemporáneo. 


\begin{abstract}
In this paper, based on a definition of the concepts of utopia and dystopia, and following the analysis methodology proposed by L. Spitzer, ten stories will be reviewed, among literary and media (television and film). The corpus studied covers almost one hundred

years of expressions, from 1924 to 2010 In these stories will be studied the way in which its creators present the dystopic universes. These universes will be seen as critical projections of living conditions experienced by human society in the contemporary world.
\end{abstract}

\title{
ANTECEDENTES
}

Para comenzar, asentemos un par de conceptos, solamente para que nos pongamos de acuerdo en aquello de lo que vamos a tratar: Determinemos lo que vamos a considerar como una distopía. El filósofo anarquista Martin Buber, en su libro Caminos de Utopía, nos dice lo siguiente:

...la visión de lo justo se consuma en la imagen de un tiempo perfecto: como escatología mesiánica; en la idea, la visión de lo justo en la imagen de un espacio perfecto: como utopía. Por su esencia, la primera trasciende lo social, se ocupa del hombre como creación, y hasta de lo cósmico; la segunda permanece circunscrita por el ámbito de la sociedad, aunque a veces entraña en su imagen una transformación interna del hombre. (Buber, 1955, pág. 18)
Si comprendemos a las distopías de la literatura de anticipación como imaginaciones anti-utópicas, debemos asumirlas pues, conceptualmente, como visiones o, mejor dicho, como previsiones de un tiempo futuro y de un espacio asolados por la imperfección y la injusticia, la ruina del mundo y la degradación de la especie humana.

Al referirnos a las distopías, como discurso de los medios de comunicación y la literatura, creo que debemos remontarnos hasta esa isla utópica de equidades, armonías y perfecciones que imaginara Tomás Moro hacia 1516, años antes de que su fe le hiciera perder la cabeza en un Londres feroz, de tiranía, intrigas palaciegas y crueldades, situado a años luz de ese paraíso que describiera en su libro, diciendo: 
Os he descrito con la mayor sinceridad el modo de ser de su República (Utopía) a la que considero no solo la mejor, sino la única digna de llevar tal nombre. Porque en otros sitios los que hablan de la República lo que buscan es su interés personal. Pero en Utopía, como no hay intereses particulares, se toma como interés propio el patrimonio público; con lo cual el provecho es para todos. En otras repúblicas todo el mundo sabe que si uno no se preocupa de sí se moriría de hambre, aunque el Estado sea floreciente. Eso le lleva a pensar y obrar de forma que se interese por sus cosas y descuide las cosas del Estado, es decir, de los otros Tomás Moro, Utopía 74 ciudadanos. En Utopía, como todo es de todos, nunca faltará nada a nadie mientras todos estén preocupados de que los graneros del Estado estén llenos. Todo se distribuye con equidad, no hay pobres ni mendigos y aunque nadie posee nada todos sin embargo son ricos. ¿Puede haber alegría mayor ni mayor riqueza que vivir felices sin preocupaciones ni cuidados? Nadie tiene que angustiarse por su sustento, ni aguantar las lamentaciones y cuitas de la mujer, ni afligirse por la pobreza del hijo o la dote de la hija. Afrontan con optimismo y miran felices el porvenir seguro de su mujer, de sus hijos, nietos, bisnie- tos, tataranietos y de la más dilatada descendencia. Ventajas que alcanzan por igual a quienes antes trabajaron y ahora están en el retiro y la impotencia como a los que trabajan actualmente. (Moro, 1984, pág. 195)

La genealogía de lo utópico que aparece, en la literatura de anticipación, como el opuesto luminoso de las distopías más oscuras y fascinantes, proviene a nuestro juico del siglo XIX, del debate entre los comunistas científicos -Marx y Engels- y los "utópicos" -Owen, Fourier, Proudhon o Kropotkin-.

Muestra de lo señalado es esta cita del Manifiesto del partido comunista:

En 1847, el concepto de "socialista" abarcaba dos categorías de personas. Unas eran las que abrazaban diversos sistemas utópicos, y entre ellas se destacaban los owenistas en Inglaterra, y en Francia los fourieristas, que poco a poco habían ido quedando reducidos a dos sectas agonizantes... Era un comunismo toscamente delineado, instintivo, vago, pero lo bastante pujante para engendrar dos sistemas utópicos: el del "ícaro" Cabet en Francia y el de Weitling en Alemania. (Marx. Karl y Engels, pág. 32)

Los "comunistas científicos" acusaban a los "comunistas utópicos" de no 
comprender las fuerzas incontenibles, verdaderas y perceptibles del cambio social, y de comprender erradamente ese cambio social apelando "a la razón, a la justicia y a la voluntad del hombre para volver a su lugar a la sociedad humana desquiciada..." (Buber, 1955, pág. 16).

De manera muy similar al planteamiento antiutópico marxista, para los pensadores conservadores, como Robert Spaemann, filósofo católico contemporáneo, las utopías son igualmente inquietantes', dice este autor:

La meta utópica de la abolición del poder legitima, en cambio, el poder incontrolado porque los posibles controladores, en cuanto esclavos de la naturaleza, es decir, seres sin emancipar, no poseen todavía el carácter de sujeto político. (Spaemann, 1980, pág. 220)

Por su lado, el liberalismo -positivo también, sustentado en el avance de la ciencia y las técnicas-, generó una idea de la sociedad futura, liberada de todos los males humanos por obra y gracia de los avances científicos y del dominio de la naturaleza que llegó hasta la alteración provechosa de la geografía, el ejemplo más contundente de esta visión: a fines del siglo XIX e inicios del XX, se cambiaron los mares, al construirse los canales de Suez y Panamá.

Los positivistas -Marx y los suyos en la izquierda y los detentadores del libre mercado en la derecha- convencidos de levantar sobre bases científicas e incontestables sus visiones del futuro, unos y otros -liberales y comunistasimaginaron sociedades armoniosas paridas por un progreso incontenible, unidireccional y luminoso. Y, científicos como eran, no las pensaron como utopías, sino como consecuencias altamente probables de un proceso obvio de crecimiento y ascenso social, cultural, político y económico.

Paradójicamente, ambos -tanto comunistas como liberales- terminaron por generar sociedades terribles: la una fruto de la revolución comunista con sus "gulags" y sus dictadores como Stalin o Kim Jong II, y la otra producto del desafuero liberal del mercado, llena de millonarios como Donald Trump, políticos banales como Donald Trump y hordas de miserables desalentados como los votantes de Donald Trump.

\footnotetext{
${ }^{1}$ Es interesante, en el contexto de este trabajo, la crítica de la perspectiva de Spaemann que hace J. Habermas, quien usa los planteamientos de F. Fanon sobre la necesidad de los colonizados de anular la dominación que sufren; impugna la insistencia de Spaemann en la necesidad de una dominación racional diciendo: "Usted, en cambio, señor Spaemann, se apresura en presentar la necesidad de un señor blanco". (Spaemann, p. 226). Más adelante, en el análisis de la obra de Karel Kapec, veremos como las ficciones distópicas encaran este problema de la dominación colonial.
} 
Es contra esas imaginaciones, contra esas dos sociedades posibles, autoritarias, cargadas de represión, banalidad e injustica, es contra estas realidades, que la ciencia ficción inventa las distopías. Insistimos: las distopías - situadas, generalmente, en el futuro- se imaginan contra situaciones sociales y políticas muy concretas del presente.

El método que aplicaremos al análisis de los discursos, en este artículo, tanto de los cinematográficos, como de los televisivos y los literarios, se inspira en la propuesta de Leo Spitzer quien en su libro Lingüística e historia literaria, desarrolla un método de interpretación de los textos, desde el análisis lingüístico en el que, a partir de un conjunto de relaciones significativas aprehendidas entre dos palabras distintas, se arriba al establecimiento de un parentesco epistemológico entre ellas, tal relación las explica. Es un método que yendo desde la superficie llega a una interioridad del sentido, que explica el problema.

Aplicando este método a la literatura -y nosotros diríamos, a otras formas narrativas como el cine o la televisión-, Leo Spitzer propone:

...puedo sugerir (al investigador), que proceda en su trabajo desde la superficie hasta el centro vital interno de la obra de arte; que observe primero los detalles en el aspecto superficial de la obra en particular... que agrupe luego esos detalles y trate de integrarlos en un principio creador que pueda haber estado presente en el alma de artista; que, finalmente, intente un hábil ataque por la espalda sobre los otros grupos de sus observaciones, para comprobar, de este modo, si la "forma interna", que ha reconstruido por vía del ensayo, da razón del conjunto de la obra. (Spitzer, 1974, pág. 32)

Como vemos, el procedimiento de Spitzer es cíclico, se trata de penetrar hacia un centro significativo -que nosotros hemos denominado tema- desde la superficie del texto narrativo, para luego, con la unidad de sentido que se haya obtenido en ese primer paso, regresar al nivel superficial para comprenderlo mejor.

Trabajemos, pues, siguiendo el método planteado, con diez manifestaciones imprescindibles del fenómeno estudiado, ordenadas cronológicamente. Los ejemplos presentados, nos parece, constituyen una muestra válida del fenómeno, tanto por su trascendencia estética, como por su difusión generalizada y por la importancia de sus creadores, sean escritores, cineastas o productores de televisión. 


\section{UNA DISTOPÍA SOVIÉTICA}

Empecemos con Bulgakov y su novela corta Huevos fatales de 1924 (Bulgakov). En esta obra, Mijail Bulgakjov -el maravilloso autor de El maestroy margarita y Novela teatral- cuenta una historia hilarante: Un científico, experimentando con unos rayos, halla una radiación que es capaz de estimular un crecimiento desproporcionado de aquello que toca: objetos inorgánicos o seres vivos. El hallazgo es tan accidental como promisorio.

Acontece este prodigio científico en la Unión Soviética de los planes quinquenales, de las grandes obras de hidráulicas e industriales. En ese contexto, la utilidad del rayo de crecimiento es obvia: producirá gallinas gitanescas, conejos enormes, bovinos ciclópeos para alimentar a toda esa masa de proletarios que, felices y agradecidos con el Estado, agachan la espalda y levantan los brazos con sus palas y taladros para construir, golpe a golpe, la grandeza de la gran patria soviética.

El problema que frustrará este plan de alimentación del proletariado, solución del hambre y fuente de la energía necesaria para la concreción de los proyectos descomunales de infraestructura que llevarían hasta las estrellas al grande y sufrido pueblo de los sóviets, el problema de este plan maravilloso surge de un malentendido generado en los intrincados procedimientos propios de la burocracia, una red tan enorme y compleja como la gran patria soviética, y muchísimo más misteriosa.

Pasa que los huevos de gallina que una oficina del Estado había enviado al científico de la historia, y que debidamente irradiados debían reventar en polluelos gigantescos, son sustituidos, en los pasillos y bodegas burocráticos, por un cargamento de huevos de reptiles destinados a poblar los zoológicos del país.

El resultado es terrible: cobras de veinte metros que se despachan de un solo bocado, al más aguerrido representante del ejército rojo, saurios del tamaño de casas que devastan y asolan la campiña soviética, destruyen las enormes fábricas y diezman la población de proletarios llevando el país a su destrucción.

Tenemos, pues, un proyecto productivo ciclópeo que se hunde por culpa de la burocracia y arrastra con un país extenso y destruye todo un pueblo. Bulgakov, con su distopía, no slo critica al totalitarismo que sufrió en carne propia, pues fue perseguido y atormentado por la policía política de Stalin, Bulgakov hace algo más sutil: critica una noción de progreso, la de las obras mastodón- 
ticas, dice que ellas, gracias a la burocracia que las sustenta, terminan por arruinar a los pueblos que, se supone, debían redimir.

\section{UNA DISTOPÍA CONTRA EL EUROCENTRISMO Y EL COLONIALISMO}

Podemos leer en la novela LA GUERRA DE LAS SALAMANDRAS, de Karel Kapec, publicada por primera vez en 1936:

¡Aló, vosotros los hombres! ¡Conservad la calma! No tenemos intenciones hostiles contra vosotros. Necesitamos únicamente más agua, más costas. Por eso tenemos que remover nuestros continentes... No podemos vivir en aguas profundas. Necesitamos de vuestros continentes para relleno de las profundidades. (Kapek, pág. 115)

Es Chief Salamander quien se dirige así a la humanidad, en nombre de sus gobernados: unos saurios grandes como perros e inteligentes que, en algún momento del siglo XX fueron descubiertos en unas islas del sur Pacífico. Esos seres han crecido, han asimilado la ciencia de los humanos y, en el presente de la novela, les hacen la guerra con éxito: hunden la mayor parte de nuestros continentes para ampliar los suyos, submarinos. Los humanos quedamos, en esta distopía, relegados a lo que fueron territorios mediterráneos; las montañas rocosas en América del Norte, supongo que Bolivia en Sudamérica... Praga, la Praga de Kapec, es en su novela un puerto marítimo. Y es que el autor de LA GUERRA DE LAS SALAMANDRAS, es checo, es decir, originario de un país periférico y escritor de un idioma periférico, quien escriba en checo apenas tiene un universo de apenas 13 millones de lectores posibles, lo que es mínimo comparado con los angloparlantes que son 1500 millones, o los hispanohablantes que somos 559 millones.

El lugar desde el que Kapec ve y comprende el mundo -esa periferia de los países que están en el límite de Europa- le permite escribir esta novela en la que su distopía de un mundo humano que es asolado por unos saurios inteligentes que surgen del mar e invaden y derriban las costas. Esos reptiles son descubiertos por marineros que los hallan entregados a un ritual primitivo; con el paso de los años y el contacto con los humanos -tecnológicamente mucho más avanzados, las salamandras 
aprenden, desarrollan sus propios conocimientos, producen sus científicos y, finalmente, retan a los humanos que los han expltado como mano de obra barata para sus proyectos de expansión en los océanos. La similitud de esdta historia ficticia con la historia verdadera del colonialismo es muy clara: Los países centrales de nuestro sistema mundial, Europa y EEUU, enfrentan hoy las hordas de habitantes de los países periféricos, colonizados que, en busca de una mejor vida, los invaden por sus fronteras globa- les: Ceuta y Melilla, el Mediterráneo entre Turquía y Grecia, o los puestos fronterizos del sur de EEUU. Con terror, nos ven llegar a sus costas y a sus ciudades, y poco pueden hacer por detenernos. Tan poco como pueden hacer los humanos de la distopía de Karel Kapec que, al final de la novela, ven el mundo sumergido en el mar y dominado por sus otrora subordinados: las salvajes salamandras, tan peligrosas ellas, a la larga, como cualquiera de nosotros, los buenos salvajes sudamericano o subsaharianos.

\section{LA DISTOPÍA DEL AUTORITARISMO}

Quizá la más conocida de las distopías literarias sea 1984 escrita por George Orwell en 1948 (Orwell, 1952), obra de la que hay una versión cinematográfica excelente protagonizada por John Hurt y por Richard Burton y filmada, precisamente, en 1984 (Radford, 1984). El autor inglés, anarquista y comprometido, fue a luchar en la guerra de España, inscribiéndose en las filas de las milicias del POUM, un partido trotskista, cercano al anarquismo, y vivió, en carne propia, la rebelión de los anarquistas en Barcelona contra los comunistas, y la respuesta brutal de los cuerpos de seguridad entrenados por los soviéticos que asesinaron, encarcelaron y torturaron a miembros de partidos de izquier- da no estalinistas, el caso de Andreu Nin fue y es clamoroso.

Con una experiencia tan de primera mano -contada en su libro menaje a Cataluña (Orwell, Homenaje a Cataluña), un modelo de novela de no ficción- Orwell traza una distopía estalinista estremecedora en la que todos los miembros de una sociedad gris de proletarios degradados repiten, alienados, los eslóganes de un gobierno brutal, son vigilados por cámaras de televisión todo el tiempo y miran idiotizados, en las pantallas de esos aparatos el rostro del líder, el Gran Hermano, por el que sienten un amor idólatra.

Podríamos preguntarnos cómo esta distopía nos ayuda a comprender el 
mundo que vivimos. ¿Nos ha alcanzado el futuro que preveía para nosotros el autor inglés? La respuesta es desalentadora: no parece que tengamos que enfrentarnos a nuevos dictadores globales como los que hubo en el pasado, en ese mundo que sí vivió el autor de 1984: nos enfrentamos a EL GRAN HERMANO, el reality show emitido por primera vez en Holanda, a fines de los años 90 y reproducido al menos en 70 versiones más, en diversos países a lo largo y ancho de este mundo globalizado.
Sí, la versión del gran dictador, amado con terror por todos, quien por medio de unos burócratas inclementes impone su voluntad torturando y mintiendo, se ha concretado en nuestro tiempo en el ejercicio ruin y embrutecedor de los medios de comunicación de masas, que consiguen -sin torturas ni crueldades- la misma alienación, la misma sumisión de las conciencias que, en 1948 aterraba a Orwell.

\section{UNA DISTOPÍA INVENTADA CONTRA LA HISTORIA}

Revisemos, a continuación, la Historia alternativa de EL HOMBRE EN EL CASTILLO de Philip K. Dick con su primera edición en 1962 (Dick). Una de las tiranías que más nos sujetan y determinan es, sin duda, la del relato histórico. Debemos asumir, aceptar lo que nos cuentan las fuentes consagradas por el Estado y la cosmovisión de cada época, y subordinarnos a ese discurso. Tenemos que creernos esas palabras de las que mana nuestra identidad más honda y sobre las que construimos, humildemente, nuestras vidas tan lejanas del fasto de los poderosos y de la épica de los próceres, es decir, de los protagonistas de esa Historia que, para nosotros es un espectáculo tan sagrado como lejano.
Dick, en EL HOMBRE EN EL CASTILLO, inventa una distopía histórica: en la novela, han ganado la Segunda Guerra Mundial los alemanes y los japoneses y, en los acuerdos de la rendición de los aliados, se han repartido EEUU. La costa pacífica está en manos del imperio japonés, la costa este es gobernada por los nazis alemanes y, entre estas dos posesiones territoriales, persisten unas repúblicas primitivas y miserables, en las Montañas Rocosas. La novela se desarrolla en una de las ciudades ocupadas por Japón, en ella los japoneses son saludados con venias sumisas por los aterrorizados estadounidenses y hay un férreo control policial.

Es interesante una escena del relato en la que un alto funcionario japo- 
nés se pierde en un parque de la ciudad -San Francisco- y, de alguna manera, entra en un universo paralelo-el nuestroen el que los EEUU son los victoriosos. Para el pobre burócrata es una pesadilla un mundo en el que los "americanos" no se humillen ante él.

Entre los antiguos aliados -Alemania y Japón- se desarrolla una "guerra fría", por la supremacía global: los protagonistas de la novela son agentes del espionaje alemán, infiltrados en territorio japonés... Los nazis tienen un mayor desarrollo tecnológico y los japoneses buscan igualarlos por cualquier medio, lícito o delictivo. En toda esa contienda planetaria, los habitantes del vencido EEUU poco o nada participan.

La pregunta que se plantea, sin duda, esta novela es: ¿Fue muy distinta la realidad que surgió del triunfo aliado en la II Guerra mundial? Veamos. Luego de la rendición de Alemania y del ataque nuclear contra Japón y su posterior sometimiento, quedaron dos súper potencias en pie en nuestro planeta. Ambas -en nuestra realidad EEUU y la URSS- emprendieron en los años cincuenta una "guerra fría" que se prologó por décadas y que puso la supervivencia de nuestra especie en grave riesgo (recordemos el incidente de los misiles en Cuba del año 1962). Repito: ¿Fue muy distinta la realidad que surgió del triunfo aliado en la II Guerra mundial, que la que imagina Philip K. Dick en EL HOMBRE EN EL CASTILLO? Y la terrible respuesta es: No. Al final, en ambas realidades, la histórica y la distópica, triunfan la codicia, el ansia delirante de poder y la crueldad.

\section{UNA DISTOPÍA ECOLOGISTA}

Una distiopía inventada contra la deforestación: Mundo Sumergido, de J. G. Ballard editada en 1962 (Ballard, 1988). La importancia de la ecología es ya parte de nuestra visión del mundo; nos preocupa a todos la destrucción de las grandes selvas como la Amazonía, la polución de los mares, la extinción de miles de especies y el cambio climático. Sabemos que estas catástrofes incidirán en el bienestar, y quizá en la posibilidad de supervivencia, de nuestros descendientes, además de ser -ya en la actualidad-causantes de alteraciones que nos afectan como el smog y la contaminación del agua.

En Mundo Sumergido, Ballard nos muestra un planeta inundado por unas mares que se han hinchado enormemente con las aguas provenientes del deshielo de los casquetes polares provocado por el calentamiento global que, 
además, ha convertido a los continentes en selvas tropicales cuya vegetación y fauna -mutantes, desproporcionadas, ávidas- devoran los asentamientos humanos expandiéndose desde las latitudes ecuatoriales hacia el norte y el sur del globo terráqueo. El delta del Támesis, por ejemplo, se parece en esta ficción -y novelísticamente hablando- al de ese río por el que se pierde, en el África negra, Kurtz, el personaje de Conrad en El corazón de las tinieblas.

El mar y la selvas calientes se pueblan de monstruos animales y vegetales $y$, entre ellos, perviven unos pocos humanos que viajan usando máquinas cada vez más herrumbradas y deterioradas -hidroaviones y lanchas de quilla plana-, haciendo esfuerzos infructuosos para salvar a unos restos de la humanidad que, paulatinamente, se hunde en la barbarie antes de desaparecer de esa exuberante faz de la tierra.

Como siempre en la literatura, la anécdota, el argumento y su trama, nos encaminan hacia profundidades de lo humano que deben estremecernos, nos sacude para que podamos, en palabras de Viktor Shlovsky, "desautomatizar" nuestra conciencia, embotada por el terror cotidiano, y ver con lucidez el mundo que nos rodea, gracias a lo que este autor Ilamó el "extrañamiento", concepto que es, sin duda, uno de los más lúcidos del Formalismo Ruso.

En esta novela, lo terrible no es esa catástrofe acuática y silvícola sino el impacto de ese apocalipsis en la conciencia humana. Los personajes del relato están perdidos, hundidos en un anegamiento de sus conciencias que los incapacita para la acción, que les impide tener conciencia del horror que viven, que los hace abúlicos e irresponsables. Convertidos en una especie de espectros lamentables de lo que fueron los humanos, se pierden en esa jungla tórrida y profusa, como si en su calor húmedo y verdoso se les hubieran evaporado las almas.

La novela termina contándonos así la última y fatal peripecia de su protagonista quien, poco a poco en ese mundo anegado, ha ido perdiendo la razón:

Dejó la laguna y entró de nuevo en la selva, y al cabo de unos pocos días había perdido el rumbo y caminaba a orillas del agua hacia el sur, bajo el calor y la lluvia crecientes, atacado por caimanes y murciélagos gigantescos, como un segundo Adán en busca de los olvidados paraísos del sol renacido. (Ballard, 1988, p. 221) 


\section{DISTOPÎA Y SOBREPOBLACIÓN}

A partir de la novela de Harry Harrison ¡Hagan sitio, hagan sitio! (Harrison, 1986) se produjo una película muy bella titulada Soylent Green y estrenada en 1973 (Fleisher, 1973). Una historia policial ambientada en un futuro terrible, de sobrepoblación, smog y miseria en el que las élites de millonarios viven de producir, con los cadáveres de sus congéneres, una pasta verdosa y nutritiva: el Soylent, que es el único alimento de la humanidad.

Podríamos pensar que el tema que enfrenta esta distopía es el de la bomba demográfica, y quizá ese fue el horror que alumbró la imaginación de Harry Harrison al escribir su novela. Con el paso de los años, creo que esta distopía de la explosión demográfica ha cedido su puesto a otra, aún más horrible: la degradación de los alimentos que compramos en supermercados que son iguales en todas partes del mundo y que comemos, mansos y resignados.

Recuerdo una escena conmovedora de la película: un viejo prepara un banquete miserable para él y su amigo, el policía protagonista de la trama, con una magra pieza de filete que ha robado este último. Mientras cenan ese miserable alimento, el anciano le cuenta al jo- ven de la época en la que se comía carne cuando se quería, y había campos de verduras y hectáreas de naranjales cuyos frutos brillaban como joyas bajo un sol limpísimo.

¿Qué comemos ahora? Soylent verde, quizá un poco menos repugnante que el de la novela, pero igual de artificial; comemos unos productos industriales -pasteles aceitosos o snaks con gusto a cartón- comemos frutos genéticamente alterados que ya no tienen los sabores que conocimos, bebemos refrescos hechos con fórmulas químicas que nos son desconocidas y carnes de animales engordados con hormonas. Los que tenemos más de cincuenta años, para nuestro mal, podemos recordar otros sabores, otros caldos y otros frutos que, como no se pueden enlatar, han desaparecido del mercado.

La traducción del título de la película al español fue: CUANDO EL DESTINO NOS ALCANCE, por una vez, los traductores mejoraron el título original, pues hace patente esa idea que el futuro nos alcanzará, tarde o temprano, con sus horrores; así queda clara la noción que dimos de distopía: una construcción imaginaria del futuro que se escribe contra el presente. 


\section{UNA DISTOPÍA DEL CONFLICTO ENTRE GENERACIONES}

La guerra del cerdo es una película dirigida por Leopoldo Torre Nielsen y estrenada en el año 1975 (Nielsen, 1975), cineasta argentino. Se trata de una adaptación de la novela de Adolfo Bioy Casares Diario de la guerra del cerdo (Bioy Casares, 2004) en la que se cuenta una historia distópica que sucede en la ciudad de Buenos Aires: Un movimiento de jóvenes, guiado por un líder carismático, empieza a cumplir una serie de acciones brutales contra los viejos, a los que denomina "cerdos" y culpa de los males de la sociedad. Los violentos, agreden, golpean y llegan a matar a los ancianos que viven con miedo, escondiéndose. El protagonista, Isidoro Vidal, sufre estas circunstancias, se distancia de su hijo, que simpatiza con los jóvenes, se junta a su grupo. amigos -todos víctimas potenciales o efectivas- $y$, al fin del relato, logra enamorar a una muchacha quien lo acompaña cuando la guerra del cerdo concluye.

La película sigue la misma narración, por lo que, en este ensayo, cabe que veamos lo que como arte visual aporta a la historia de Isidoro Vidal y la guerra contra los viejos. Torre Nielsen nos muestra una ciudad de conventillos y casa viejas, unas calles ganadas por unas sombras plácidas, que se despliega en la pantalla con el ritmo lento, del jazz de Gato Barbieri. Con este recurso, esa realidad violenta y alternativa que nos relata, se apareja y solapa con la vida propia de una urbe acogedora, de viviendas comunitarias en las que los vecinos comparten sus vidas, en los patios, con una solidaridad que la modernidad termina por eliminar. Ese entorno entrañable -logro cinematográfico de Torre Nielsen-es el que, parece, derrota a las fuerzas de los jóvenes airados que terminan por disolverse, luego de una ataque excesivo en el que muere un número importante de viejos. El patriarcalismo y su contrapartida de revisión revolucionaria de los valores y las conductas, ambos exacerbados por la modernidad, se ponen en crisis en este relato.

\section{IDENTIDADES Y DISTOPÍAS}

Podemos citar como una distopía impugnadora de los discursos identita- rios propios de nuestro tiempo: la inventada por Huilo Ruales en su libro Fetiche 
y Fantoche. En una parte de esta novela corta, ganadora del premio Espinosa Pólit de 1994 y publicada en ese año, Huilo Ruales nos presenta esta escena que acontece en el interior de la iglesia de Santo Domingo, en Quito:

...empieza a caminar hacia el interior de la iglesia, la virgencita se dirige hacia la nave izquierda: hacia el ángulo de piedra tallada en donde -antes del terremoto del 96 y los consecuentes saqueos- se erigía con ribetes de pan de oro y encofrados de madera el altar de san antonio de padua. hoy no es sino un rincón, un muro oscurecido con el hollín de cocinetas y reverberos de las comidas y canelazos... La nave central ha perdido casi todo su techo barroco y la mayor parte de sus cúpulas antes pobladas de querubines rechonchos, asido de sus cornetas. Por eso la tempestad se precipita en el templo... (Ruales, Fetiche y Fantoche, 1994, pág. 12)

Esta secuencia apocalíptica sucede en un Quito de fines del siglo XX o inicios del XXI, una ciudad destrozada por un terremoto y que alberga, entre sus ruinas, a unos quiteños que sobreviven en la miseria, organizados en pandillas, entre la violencia y el crimen. No hay visos de esperanza para esos quiteños que transitan por unas calles llenas de escombros y bajo una lluvia gris y sempiterna.

Hay al menos una novela más que trata de un futuro distópico para Quito: Los años perdidos de Juan Pablo Castro Rodas, cuya acción se inicia en un Quito resquebrajado por un verano permanente que ha convertido a la lluvia en un recuerdo casi de leyenda. Distopías referidas a Guayaquil las podemos encontrar en tres novelas que la inventan destruida, hundida en las aguas de mar, imaginaciones ligadas con el fin de los tiempos: Río de Sombras de Jorge Velasco Mackenzie, La era del asombro de Fernando Naranjo y $\underline{\underline{E}}$ libro flotante de Caytram Dölphin de Leonardo Valencia.

¿Qué imaginaciones y preguntas nos plantea, a los habitantes de esta ciudad, la distopía de Ruales? La respuesta a esta pregunta es muy amplia y diversa, centrémonos en uno de sus muchos temas: el de la identidad.

Amin Maalouf, escritor libanés, se plantea en un libro titulado Identidades Asesinas (Maalouf, 1998), la idea de que si, en vez de cultivar en nosotros una identidad múltiple y mutante, nos aferramos a una identidad monolítica y excluyente, nos estamos poniendo en la senda atroz y ciega de los que matan al otro cuando es distinto y solo porque es distinto. Maalouf, originario de la ciudad en la que se dieron las masacres de Sabra 
y Chatila, tristemente sabe muy bien de lo que nos está hablando.

Los quiteños, afortunadamente, no llegamos a extremos tan dramáticos como los de los beirutíes. En nuestro pasado, desde inicios del siglo XX y exceptuando la cruenta "Guerra de los 4 días" de 1932, no hay grandes masacres ni hechos de horrible violencia -sin duda porque con nosotros la Historia ha sido extrañamente benigna-; pero sí que tenemos, los quiteños, una identidad que podríamos cuestionar a la luz apocalíptica de la pequeña novela de Ruales.

¿Cuánto pesan, en la construcción de nuestra identidad estas amadas piedras que nos rodean y los bienes culturales -rituales, imágenes y esculturas- que entre ellas se albergan? ¿Hay otros núcleos alrededor de los cuáles construimos la imagen de lo que somos? No estoy seguro que existan otros núcleos de lo quiteño, a más de unas tradiciones cada vez más desvaídas y de una conciencia de centralidad que proviene de nuestra condición de capitalinos y que es vista casi con desagrado por el resto de ecuatorianos. Si, como en la ficción de Ruales, estas piedras desaparecieran machacadas por una catástrofe cualquiera, ¿de qué otros hitos afectivos o estéticos nos asiríamos para construirnos identitariamente? Si esas piedras desaparecieran, nos convertiríamos en seres parecidos a los personajes que pueblan el relato de Ruales, que son hombres y mujeres desarraigados, desorientados y vacíos? Como se puede ver, la distopía construida en las páginas de Fetiche y Fantoche genera poderosas interrogantes, función esta, por lo demás, propia de lo literario.

\section{DISTOPÍA Y ZOMBIS}

The Walking Dead es una serie de televisión desarrollada a partir de un cómic creado por Robert Kirkman en el año 2003 (Darabont, 2010). En este, se relata la lucha de un grupo de humanos que en Estados Unidos, en Kentucky, sobreviven a un Apocalipsis biológico: Una enfermeras que convierte en zombis a quienes mueres, independientemente de la causa de su muerte. Un alguacil,
Rick Gimes, se organiza con otros humanos no contaminados para enfrentar a los muertos vivientes y subsistir. En el proceso de sobrevivir, el grupo de Gimes se encontrará con otros grupos de humanos que, ante el hundimiento de la sociedad, provocado por la catástrofe, reaccionan y se organizan de diversas maneras, usualmente recurriendo a la violencia y la brutalidad. El mismo algua- 
cil, al evolucionar la historia, irá transformándose en un líder autoritario y cruel que se opondrá a otros líderes y grupos aún peores, tanto en entornos rurales como en espacios urbanos degradados.

En la adaptación a la televisión, del año 2010 y creada en Estados Unidos por la productora American Movie Clasics, se conservan los mismos hechos narrados y los mismos caracteres, aunque algunos personajes se simplifican, según señala Andrely Nieto es su estudio (Nieto, 2016). En ambas versiones -el cómic y la serie de televisión-, la premisa básica se conserva: "Teme a los vivos", pues si bien los muertos que perviven son un peligro permanente y ubicuo, son las relaciones de unos humanos embrutecidos por el horror de la catástrofe las que se muestran como los obstáculos que tienen que vencer los personajes para lograr su meta: sobrevivir.

Cabe señalar que en nuestro país se ha escrito una novela con el tema de una distopía zombi, titulada 1842, ciudad muerta (Quevedo, 2015) del autor Décimo Quevedo, hay planes para convertir esta obra de una película.

\section{LA DISTOPÍA DE LAS NUEVAS TECNOLOGÍAS DE LA COMUNICACIÓN Y LA INFORMACIÓN}

Black mirror (Brooker, 2011) es una serie de televisión creada en la Gran Bretaña desarrollada por Charlie Brooker y producida por la empresa Zeppotron, que se presenta en la televisión desde el año 2011 y que lleva ya tres temporadas. En esta, se presentan situaciones distópicas relacionadas con la tecnología de la comunicación, no solo las Nuevas Tecnologías de la comunicación y la información, como los teléfonos celulares, las tablets o las aplicaciones que permiten operar a las redes sociales, sino también tecnologías anteriores pero de gran incidencia social como la televisión. En cada episodio -cada uno es una historia distinta de la anterior- se muestra una historia extrema relacionada con uno de los recursos de las tecnologías mencionadas, con el uso patológico que de ellas hacemos en nuestro mundo real. En el primer episodio, se cuenta la historia de secuestro de una princesa británica adorada por su pueblo, ante el plagio, se moviliza toda la sociedad. El secuestrador exige, para la liberación de la aristócrata, algo inusual y atroz: que el Primer Ministro de la Gran Bretaña mantenga relaciones sexuales con una cerda, en una especie de escabroso reality show, que deberá ser pasado por la televisión nacional. Para aumentar la presión, apa- 
rece un dedo cortado que se presume es de la princesa. La opinión pública exige que el político cumpla con la demanda del secuestrador y el Primer Ministro -un joven político que tiene por delante una carrera prometedora- acaba accediendo a la exigencia. Todo el país mira la escena, durante la cual las calles se vacían y los pubs se llenan de televidentes que reaccionan ante lo que ven con una mezcla de repugnancia, conmiseración y deleite culposo. Al final del episodio, se descubre que el secuestrador es un artista -quien se ha cortado su propio meñi- que para enviarlo a las autoridades como si se trata del dedo la princesa, y que al final se suicida- que ha realizado así una retorcida y descomunal performance; y se ve al Primer Ministro consolidado como un político exitoso. Es, como se ve, una visión implacable de la sociedad del espectáculo que la televisión ha construido, en la que todo debe ser un show, sin límites éticos ni estéticos. Es, también, una crítica a una parte del arte contemporáneo, que se genera de espaldas a una sociedad que desprecia.

\section{CONCLUSIONES}

Para concluir, podemos señalar que en los distintos géneros expresivos $y$ en las diez diferentes historias que hemos presentado, hay siempre un elemento mediador de la distopía. Este elemento que genera la situación distópica puede ser socio - político, como en el caso de La guerra del cerdo, 1984, Cuando el futuro nos alcance o El hombre en el castillo; puede ser ecológico - telúrico, como en el caso de Mundo sumergido, Fetiche y Fantoche y La guerra de las salamandras; puede ser tecnológico, como en Black mirror o Huevos Fatales; 0 puede ser biológico, como en el caso de Walking dead.
En todos los casos señalados, e independientemente de la mediación generadora de las distopías, se trata de desviaciones del proyecto de progreso, superación y control del mundo propio de la modernidad, son desviaciones perversas de ese proyecto que terminan por expresarse en catástrofes que ponen en grave riesgo la viabilidad de la sociedad humana.

En todos los casos, también, esas desviaciones del ideal moderno inciden en la ética delos afectados, en la conducta de unas sociedades que, al ser llevadas a situaciones extremas, deben buscar en su acervo espiritual y ético para luchar por la subsistencia. 
Parecen decirnos, los creadores de estas distopías, que los humanos ni somos capaces de hallar respuestas éticas y perspectivas espirituales que garanticen nuestra pervivencia.

Por tanto, podemos afirmar en concordancia con lo que planteáremos al inicio de este trabajo, que las distopías son, sobre todo, luminosas críticas de la modernidad, de sus valores y de sus logros.

Citábamos, a lo largo de este ensayo, el título de una clásica película de tema distópico: CUANDO EL FUTURO NOS ALCANCE. Podemos concluir este trabajo señalando lo advertido por las narrativas distópicas se ha hecho realidad: Nos ha alcanzado el futuro, con reality shows y memez generalizada; es así como las distopías, brillantemente imaginadas por escritores y guionistas, han terminado por devenir en realidades de una pobreza espiritual tan peligrosa como lamentable. 


\section{BIBLIOGRAFÎA}

Ballard, J. (1988). El mundo sumergido. Barcelona: Minotauro.

Bioy Casares, A. (2004). Diario de la guerra del cerdo. Madrid: Alianza.

Brooker, C. (Dirección). (2011). Black Mirror [Película].

Buber, M. (1955). Caminos de utopía. México: FCE.

Bulgakov, M. (s.f.). Huevos fatales. Recuperado el 2 de enero de 2017, de http://assets.espapdf.com/b/ Mijail\%20Bulgakov/Los\%20huevos\%20fatales\%20(3238)/Los\%20 huevos\%20fatales\%20-\%20Mijail\%20Bulgakov.pdf

Darabont, F. (Dirección). (2010). The Walking Dead [Película].

Dick, P. K. (s.f.). Recuperado el 3 de enero de 2017, de http://www.ddooss. org/libros/Philip_Dick.pdf

Fleisher, R. (Dirección). (1973). Soylen Green [Película].

Harrison, H. (1986). Hagan sitio, hagan sitio. Barcelona: Orbis.

Kapek, K. (s.f.). La guerra de las salamandras. Recuperado el 9 de junio de 2016, de files.yuyarina.webnode.es/200000018.../La\%20guerra\%20de\%20las\%20salamandras....

Maalouf, A. (1998). Identidades Asesinas. Madrid: Alianza.
Marx. Karl y Engels, F. (s.f.). Archivo marxista. Recuperado el 12 de dicuembre de 2016, de www.marxists. org/esánol/m-e/1840s/48-manifhtm

Moro, T. (1984). Utopía. Barcelona: Orbis.

Nielsen, L. T. (Dirección). (1975). La guerra del cerdo [Película].

Nieto, A. (15 de diciembre de 2016). The walking dead: del cómic a la televisión y contraste de la narrativa entre la capacitación audiovisual y el cómic. The walking dead: del cómic a la televisión y contraste de la narrativa entre la capacitación audiovisual y el cómic. Quito, Pichincha, Ecuador: S.e.

Orwell, R. (1952). 1984. Barcelona: Destino.

Orwell, R. (s.f.). Homenaje a Cataluña. Recuperado el 3 de enero de 2017, de Libros.dot: http://www. bosquedeniebla.com.mx/docs/ Libros/Homenaje\%20a\%20Cataluna.pdf

Quevedo, D. (2015). 1842, ciudad muerta. Guayaquil: Comics.

Radford, M. (Dirección). (1984). 1984 [Película].

Ruales, H. (1993). Fetiche y Fantoche. Quito: PUCE.

Ruales, H. (1994). Fetiche y Fantoche. Qui- 
to: PUCE.

Spaemann, R. (1980). Crítica de las utopías

políticas. Pamplona: Enunsa.
Spitzer, L. (1974). Lingüística e historia literaria. Madrid: Gredos. 